Fecha de recepción: diciembre 2017

Fecha de aceptación: marzo 2018

Versión final: julio 2019

\section{El futuro de los plásticos o los plásticos del futuro}

Carlos Torres de la Torre *

Resumen: En los últimos tiempos políticos, activistas ambientales, periodistas y otros líderes de opinión han dirigido sus armas contra los plásticos. Este mal concepto nace como resultado de los cambios en el entorno como consecuencia de la utilización de nuevas fuentes de energía, tanto nuclear como la de combustibles fósiles y el desarrollo de la industria petroquímica en especial la de los plásticos que se da a partir del descubrimiento del petróleo. Sin embargo y a pesar de las consideraciones ambientales el plástico ha construido nuestro mundo hasta el punto en que hoy es difícil imaginar nuestra vida sin él.

Muchos diseñadores han sostenido desde mediados del siglo XX, que los artículos de buena calidad pueden ser bellos y no tienen que costar mucho dinero. El matrimonio de diseñadores formado por Charles y Ray Eames proponían proporcionar a la gente lo mejor al precio más bajo posible, para ello emplearon en sus diseños aluminio, madera contrachapada, algunos otros materiales y principalmente plástico. La opinión del diseñador francés Philipe Starck, concuerda con la de sus antecesores. Le gusta este material por sus posibilidades democráticas y porque a diferencia de los materiales naturales es producto de la inteligencia humana, perfecto para nuestra civilización humana. Sostiene que desde una perspectiva ecológica que es preferible utilizar plástico en lugar de madera. El diseñador danés Verner Panton no se sentía inspirado por las fibras naturales ni la madera. Imaginaba formas orgánicas y colores chillones. Le atraían los materiales nuevos surgidos luego de la segunda guerra mundial, Perfiles de acero, madera contrachapada y sobre todo plásticos. A principios de los sesenta ya tenía reputación por sus diseños lúdicos. Amobló un hotel con muebles de plástico inflable, diseño paneles de pared de plástico retro iluminado, lámparas en forma de ovni y sillas con cilindros de metal laminado y gracias a la tecnología de moldeo por inyección de plástico creó su famosa silla de una sola pieza. Con una mirada más crítica, muchos objetos plásticos han sido cuestionados aún por la gente de la misma industria. Una evolución barata de la silla de una sola pieza fue la silla monoblock en la que se usa el mínimo material posible. Rolf Fehlbaum, presidente de Vitra Design afirma que se puede percibir la idea de bajo precio implícita en el producto, que la silla sugiere un mínimo moral: como hacerlas lo más baratas posible para que duren pocos años y luego las puedas tirar.

Entonces cabe preguntarse si es posible proteger el entorno sin prescindir de las ventajas que presentan los plásticos y sus propiedades y que estos vuelvan a ser considerados una solución a los problemas ambientales como lo fueran en 1936 cuando una mujer dijo luego de visitar la exposición El Mundo Maravilloso de la Química, «Es maravilloso cómo DuPont está mejorando la naturaleza». 
Ya que toda la industria del plástico admite que este tiene que ser más sostenible el futuro de los plásticos y el de la industria depende de hacerlos más seguros para la gente y para el planeta.

Hay una gran cantidad de intentos por obtener los llamados «plásticos verdes». Este es el sector de la industria que crece más rápidamente, aproximadamente $10 \%$ al año. Hay quienes están experimentando con materias primas renovables, devolviendo a la industria a sus raíces al utilizar material vegetal como en la época del celuloide.

Si estas propuestas resultan exitosas tal vez nuestro futuro no esté en el camión de la basura y podamos promover una mayor utilización de plásticos no contaminantes que conserven la libertad para diseñar que caracteriza a estos materiales redefiniendo lo que un crítico alemán denominó Plastikoptimismus.

Palabras clave: Plásticos - Ecología industrial - Sostenibilidad - Plásticos verdes - Materias primas renovables - Bioplásticos.

[Resúmenes en inglés y portugués en las páginas 250-252]

${ }^{(*)}$ Carlos Torres de la Torre. Doctorando en Diseño por la Universidad de Palermo y Magíster Scientiae en Gestión Empresarial. Actualmente se dedica a la investigación y docencia en la Pontificia Universidad Católica del Ecuador. Ha sido profesor de Diseño de Productos, Diseño Industrial y Marketing en varias universidades del Ecuador. Miembro del Comité Académico del Congreso Latinoamericano de Enseñanza del Diseño. Miembro del Comité de Honor del Diseño Latinoamericano del Foro de Escuelas de Diseño. Miembro del Comité de Arbitraje Internacional de las publicaciones de la Universidad de Palermo. Editor general de la revista de divulgación científica de la Asociación Ecuatoriana de Ingeniería Sanitaria y Ambiental; Ciencia e Ingeniería Ambiental. Fundador y presidente de Graffito, Industria Creativa. Sus líneas de investigación son Diseño ecológico, Diseño de servicios y Diseño inmaterial.

\section{Introducción}

La humanidad ha estado rodeada de plásticos por décadas, a pesar de su ubicuidad, de repente se ha decidido que este material es una cosa muy mala. Esta revuelta mundial en contra del plástico alcanza todos los niveles de la sociedad. Según Buranyi (2018) En los niveles más altos del gobierno, el pánico provocado por el plástico puede asemejarse a una respuesta caótica ante un desastre natural o una crisis de salud pública y sostiene que las Naciones Unidas han declarado una "guerra" contra el plástico de un solo uso.

A pesar de que la comunidad científica ha venido evidenciando los problemas ambientales debidos a los plásticos por al menos tres décadas, este arranque de ira pública es reciente. 
Los informes sobre acumulación de plásticos en los océanos datan de los años sesenta del siglo pasado y los estudios sobre la presencia de restos plásticos en tejidos humanos son anteriores. Grandes activistas ambientales como Amigos de la Tierra o Greenpeace no habían tomado acciones contra los plásticos antes de 2015.

No se puede determinar con claridad cuándo empezó a disminuir el atractivo por estos materiales al punto de generar un rechazo tan fuerte y notorio como el de los últimos tres años. El desarrollo de la industria del plástico y el incremento en su consumo no fueron consecuencia de debate político ni otro tipo de decisión meditada. Tampoco tuvieron en cuenta el impacto ambiental o el bien común. Son el resultado de la posibilidad que ofrecía el nuevo material de obtener abundancia a bajo precio, algo que no se había considerado malo nunca antes en la historia humana.

Este rechazo visceral parece impulsado por las imágenes viralizadas por las redes sociales de basura compuesta por objetos plásticos reconocibles como bolsas y botellas, que prenden ilustrar islas de basura flotante en los océanos. Sin embargo, como defiende Freinkel (2012), estas imágenes están muy alejadas de la realidad. Los vórtices formados por las corrientes marinas no están llenos de desechos. Quienes han viajado hasta allí describen un lugar de belleza singular, donde en un día tranquilo las aguas son transparentes y de un azul cerúleo, mientras que en la noche la superficie resplandece con rastros bioluminiscentes de un verde fantasmagórico trazados por los peces que acuden allí a alimentarse. Es frecuente encontrar algún objeto de plástico identificable, pero no son omnipresentes. Lo que hay son cantidades enormes de trozos minúsculos en suspensión.

Parker (2018) narra la historia protagonizada por Richard Thompson, un ecologista marino quien durante una limpieza de playas en la isla de Man, en medio del mar de Irlanda, se puso a buscar cosas pequeñas: las partículas minúsculas que yacen en la arena en la línea de pleamar. Al principio, no tenía la certeza de que fueran plásticos, debió consultar con químicos forenses para confirmarlo. Para describir estas partículas, Thompson acuñó el término microplásticos. Son estos pedacitos los que se acumulan a gran escala en el mar.

\section{Bueno, bonito y barato}

El plástico tiene un origen orgánico y es tan natural como el papel, el acero o cualquier otro material manufacturado, pero a diferencia de otros materiales más tradicionales, no se disuelve, no se oxida ni se descompone en un lapso de tiempo corto. A pesar de esta resistencia en apariencia sobrenatural es un material de costo muy bajo, quizá esa sea la razón por la que los objetos producidos con él se conciban en función de una vida útil corta y puedan ser desechados sin remordimientos. Las cualidades del plástico son tales que en sus primeros momentos la gente estaba dispuesta a creer solo cosas buenas de él. Muchos diseñadores han sostenido desde mediados del siglo XX, que los artículos de buena calidad pueden ser bellos y no tienen que costar mucho dinero. El matrimonio de diseñadores formado por Charles y Ray Eames proponían proporcionar a la gente lo mejor al precio más bajo posible, para ello emplearon en sus diseños aluminio, madera contrachapada, algunos otros materiales y principalmente plástico. Este último ofrece innumerables posibilidades pare el diseño, puede ser suave en una tela que no requerirá planchado, elás- 
tico en otros textiles, enmarañado en una tira de velcro, rígido en un casco de seguridad o flexible en un molde de silicona.

Muchos de los plásticos de uso común en la actualidad se desarrollaron durante la segunda guerra mundial, puesto que el ejército de los Estados Unidos estimuló la sustitución de aluminio, latón, acero y otros metales estratégicos para fines militares por plástico. El origen de los plásticos sintéticos se remonta a 1907 cuando el belga Leo Baekeland inventó un material compuesto totalmente por moléculas que no se encontraban en la naturaleza. Baekeland, buscaba una manera práctica, de aislar los elementos eléctricos, por lo mismo, desde su invención, la bakelita fue utilizada para fabricar interruptores, enchufes y más material eléctrico. Esta resina tiene la propiedad de producir un plástico termoestable ya que una vez que se enfría no puede volver a ablandarse. Los plásticos semisintéticos existían ya desde mediados del siglo XIX desarrollados a base de celulosa con la intención de sustituir materiales naturales escasos como el carey o el marfil.

La incipiente industria del plástico se dio cuenta de que se podía hacer casi cualquier cosa con él. Silenciosamente y producto tras producto fueron enfrentando a los materiales tradicionales y ganándoles la batalla. La opinión del diseñador francés Philipe Starck, concuerda con la de sus antecesores, los Eames. Le gusta este material por sus posibilidades democráticas y porque a diferencia de los materiales naturales es producto de la inteligencia humana, perfecto para nuestra civilización humana. Sostiene que desde una perspectiva ecológica que es preferible utilizar plástico en lugar de madera. En muchos sentidos son indudables las ventajas de los plásticos sobre los materiales naturales.

En el año 1977 una conocida fábrica de productos plásticos lanzó una campaña basada en la frase "También a nosotros en Kartell nos gusta la madera y lo demostramos". Según la empresa la campaña invitaba al lector a no caer en el error de considerar el plástico un material sin cualidades destacables ni características propias, sino una alternativa válida a los materiales naturales, capaz incluso de contribuir a la conservación del patrimonio natural del planeta.

Los indios Otavalo en el Norte de Ecuador, probablemente los indios más prósperos de América, hace mucho tiempo ya reemplazaron el hilo de algodón y la lana por una fibra acrílica, sintética elaborada a partir de acrilonitrilo que la corporación Dupont registró bajo el nombre de Orlón. En la actualidad en su mercado de ponchos se pueden encontrar tapices, textiles de diversos tipos y prendas de vestir fabricados en su mayoría con fibras sintéticas. Su vestimenta tradicional que a pesar de haberse ido adaptando a nuevas realidades y necesidades, conserva su apariencia desde mediados del siglo XX; ha sustituido para su elaboración las materias primas naturales por textiles sintéticos. Actualmente proveen de trajes tradicionales, elaborados a partir de fibras plásticas a otros grupos étnicos. El diseñador danés Verner Panton no se sentía inspirado por las fibras naturales ni la madera. Imaginaba formas orgánicas y colores chillones. Le atraían los materiales nuevos surgidos luego de la segunda guerra mundial, Perfiles de acero, madera contrachapada y sobre todo plásticos. A principios de los sesenta ya tenía reputación por sus diseños lúdicos. Amobló un hotel con muebles de plástico inflable, diseño paneles de pared de plástico retro iluminado, lámparas en forma de ovni y sillas con cilindros de metal laminado y gracias a la tecnología de moldeo por inyección de plástico creó su famosa silla de una sola pieza. 
Como afirma Annicchiarico (2012) No solo ha cambiado el paisaje doméstico, también el país ha cambiado, refiriéndose a Italia. Con los objetos también cambia el país que se mira en aquellos objetos, que los utiliza y que se reconoce en ellos de alguna forma. Los objetos son bellos, comunican, emocionan, divierten, construyen y distribuyen identidad.

Los plásticos actualmente ofrecen grandes ventajas frente a otro tipo de materiales. Brindan un alto grado de libertad en el diseño y configuración de productos, las nuevas tecnologías para procesarlos permiten fabricar productos con un número reducido de partes y piezas. Como consecuencia de la reducción el tamaño de los componentes y la reducción significativa del número de piezas individuales, se reduce el peso total de los productos de plástico.

Mediante el uso de recubrimientos o capas específicas, se puede lograr una alta resistencia física y química que evita adicionalmente la penetración de sustancias haciéndolos impermeables. Las capas superiores duras o autocurables ofrecen una alta resistencia a la abrasión y al rayado.

La perfecta integración con fibras de refuerzo proporciona una mayor resistencia contra los impactos mecánicos. Es posible integrar componentes electrónicos directamente en las partes del objeto.

En la actualidad no es difícil encontrar aplicaciones para las que los plásticos resultan difícilmente remplazables. Los plásticos inteligentes están a nuestro alcance y se utilizan tanto para objetos cotidianos como para aplicaciones especializadas. Los ejemplos incluyen usos en el desarrollo de empaques que protegen contenidos sensibles como alimentos, pudiendo indicar su contaminación o descomposición; o medicamentos sensibles a los cambios de temperatura.

Las viviendas cuentan con elementos de aislamiento eficientes y elementos de iluminación integrados con varios tipos de sensores y actuadores. Los campos de la domótica y la inmótica se benefician de la perfecta integración de los componentes electrónicos y la ausencia de controles mecánicos, los paneles de control delgados y con superficies sensibles al tacto o las unidades de comunicación que abren formas completamente nuevas de diseño y control de dispositivos. Los elementos de iluminación se benefician de lentes de plástico sobre circuitos fotónicos que contienen diodos emisores de luz o de componentes de estado sólido de alta eficiencia basados en tecnología de diodo orgánico plástico.

La ingeniería biomédica presenta un campo fértil para aplicaciones de plásticos de alta tecnología. Los elementos de forma compacta, los tableros de circuitos flexibles y un alto grado de libertad en el diseño son importantes para los dispositivos portátiles, que se pueden usar para sistemas de monitoreo de salud. Sensores montados en equipos para detectar factores de riesgo de enfermedad o incluso enfermedad temprana para un gran número de personas aparentemente sanas.

Los plásticos ofrecen a la industria del transporte productos versátiles de alto rendimiento que satisfacen una variedad de requisitos, pero siempre en conformidad con los parámetros cada vez más estrictos para la seguridad, el rendimiento, bajo costo y reducción de emisiones de dióxido de carbono.

El plástico puede imitar e incluso sustituir a materiales escasos y valiosos, también pueden resultar en imitaciones baratas y de mala calidad. Con una mirada más crítica, muchos objetos plásticos han sido cuestionados aún por la gente de la misma industria. Una evo- 
lución barata de la silla de una sola pieza diseñada originalmente por Verner Panton, fue la silla monoblock en la que se usa el mínimo material posible. Rolf Fehlbaum, presidente de Vitra Design afirma que se puede percibir la idea de bajo precio implícita en el producto, que la silla sugiere un mínimo moral: como hacerlas lo más baratas posible para que duren pocos años y luego las puedas tirar.

\section{¿De qué están hechos los plásticos?}

El término plástico se refiere a un estado del material, no al material en sí, es una forma de referirse a materiales compuestos a base de polímeros capaces de entrar en un estado plástico. A más de los polímeros, estos materiales están formados por algunos componentes adicionales, entre ellos destacan los catalizadores, los aditivos, las cargas, los refuerzos y los pigmentos.

Los polímeros son macromoléculas formadas por reacciones de polimerización en las que se unen muchas moléculas pequeñas. Las reacciones de polimerización pueden ser de adición en las que unos monómeros se unen a otros a modo de eslabones de una cadena o de condensación en las que por cada nuevo monómero que se une a la cadena se libera una molécula de pequeño tamaño, por ejemplo, agua $\left(\mathrm{H}_{2} \mathrm{O}\right)$. La mayoría de los plásticos se fabricaban originalmente con resinas de origen animal, como la caseína de la leche, o vegetal principalmente aceites obtenidos de semillas, celulosa extraída del algodón, el furfural proveniente de la cáscara de la avena, derivados del almidón o el carbón.

A pesar de que la producción del nylon se basaba originalmente en el carbón, el aire y el agua, y de que el nylon 11 se fabrique todavía con semillas de ricino, la mayoría de los polímeros se obtienen en la actualidad a partir de derivados del petróleo. Las materias primas derivadas del petróleo son tan baratas como abundantes.

Los catalizadores tienen la misión de iniciar y acelerar el proceso de reacción química.

Por su parte los aditivos tienen como misión mejorar las cualidades del polímero. El principal tipo de aditivo es el plastificante que sin alterar la estructura del polímero contribuye a incrementar su flexibilidad, blandura y procesabilidad. Más del 60\% de la producción mundial de ftalatos se emplea como plastificante para el vinil que de otro modo sería duro y quebradizo. La apariencia suave y cauchosa de algunos productos de vinil se debe a la presencia de ftalatos en cantidades, en algunos casos, superiores al $40 \%$ del material total. Según sostienen Smith y Lourie (2009) los ftalatos son responsables de problemas de salud que llegan a afectar inclusive la función testicular en niños pequeños.

Exponer un plástico a la luz es como arrojar dardos a una tela, al principio parece no suceder nada, pero con cada impacto las fibras se van rompiendo. Los plásticos son terriblemente fotodegradables. Para minimizar el efecto destructivo de la luz, se añaden estabilizantes. Entre otras funciones de los aditivos está evitar la acumulación de cargas estáticas, mejorar la conductividad eléctrica casi al nivel de los metales y un largo etcétera. Cargas: se añaden a la materia básica con el fin de abaratar el producto y mejorar algunas de sus propiedades físicas. Las cargas extensoras ocupan espacio lo que contribuye a reducir la densidad del plástico, aumentar su capacidad de aislamiento y reducir el costo de formulación. Las cargas funcionales se utilizan para mejorar propiedades del plástico tales 
como la conductividad térmica, la resistencia eléctrica, la fricción, la resistencia al desgaste y la resistencia al fuego entre otras. Las cargas elásticas se incorporan en termoplásticos rígidos para mejorar su resistencia al impacto y la fractura, aunque disminuyen la rigidez y la resistencia térmica.

El refuerzo es junto a la matriz el segundo componente de un material compuesto. Su presencia define la mayor parte de las características mecánicas del material. Supone hasta el $80 \%$ del volumen del material compuesto y tiene la función de soportar cargas. Como refuerzos se suelen utilizar fibras textiles, fibras de vidrio, fibra de carbono, algunas fibras poliméricas o materiales híbridos.

Las substancias que aportan un color más atractivo al producto, se clasifican en dos categorías: colorantes o pigmentos. Los colorantes son solubles en el medio de aplicación, tienen bajo índice de refracción, alta solidez a la luz, a la temperatura, elevado poder tintóreo $\mathrm{y}$ alto brillo. Los pigmentos pueden actuar como inhibidores de hongos y como agentes antiestáticos, son insolubles, poseen alto índice de refracción y el medio de aplicación no los afecta química ni físicamente.

\section{El Mundo maravilloso de la Química}

Explicada de alguna manera la composición de los plásticos se puede ahora pretender una mirada al posible futuro de estos.

Según narra Freinkel (2012), una mujer dijo en 1936, luego de visitar la exposición El Mundo Maravilloso de la Química, "Es maravilloso cómo Du Pont está mejorando la naturaleza". Entonces cabe preguntarse si es posible proteger el entorno sin prescindir de las ventajas que presentan los plásticos y sus propiedades y que estos vuelvan a ser considerados una solución a los problemas ambientales.

En cuanto a los polímeros, hay una gran cantidad de intentos por obtener los llamados "plásticos verdes". Este es el sector de la industria que crece más rápidamente, aproximadamente $10 \%$ al año. Hay quienes están experimentando con materias primas renovables, devolviendo la industria a sus raíces al utilizar material vegetal como en la época del celuloide. Según sostiene Manahan (2007) la mayoría de los procesos sintéticos verdes cuentan con materias primas renovables en contraste con los polímeros basados en el petróleo. Mientras que la síntesis tradicional de los polímeros implica condiciones severas, consumidoras de energía y potencialmente peligrosas, las síntesis verdes son procesos biológicos que funcionan bajo condiciones moderadas y su resultado tiende a ser biodegradable.

La biodegradación es un proceso progresivo que se da por acción natural de bacterias, hongos o algas. El material se convierte en un período de tiempo corto en dióxido de carbono, biomasa, sales minerales y agua o metano según la descomposición sea aeróbica o anaeróbica. La biomasa es materia orgánica susceptible de ser aprovechada como fuente de energía. Los polímeros biodegradables tienen sus ventajas, se pueden procesar mediante técnicas tradicionales con un menor consumo energético debido a menores perfiles de temperatura y con menor emisión de gases de efecto invernadero en comparación con los polímeros tradicionales. 
Hay una corriente fuerte por promover el uso de plásticos biodegradables, sin embargo, la biodegradación no es la única forma de fragmentación de estos. Se ha dicho ya que son fotodegradables, esto es que la exposición a la luz produce una pérdida significativa y permanente de propiedades del material. A más de esto la degradación puede ser térmica, mecánica o causada por oxidación. Si se desea un polímero intencionalmente degradable se puede provocar oxidación con el empleo de aditivos dando lugar a los llamados polímeros oxo-degradables.

De la Cruz (2018) defiende la fabricación de polímeros que en su proceso de desintegración no dejan residuos tóxicos. Se obtienen del almidón de maíz o de papa, de la proteína de soya, del etanol extraído de la caña de azúcar y del ácido láctico. De su procesamiento se obtiene ácido poliláctico PLA y polihidroxialcanoatos PHA estos biopolímeros darán lugar a la fabricación de plásticos ecológicos.

Según Eun et al. (2018). Sang Yup Lee, un profesor de la Universidad Kaist, de Seúl, y un equipo de investigadores de la empresa química coreana LG Chem, utilizaron una modificación metabólica de la bacteria Escherichia coli con la que lograron sintetizar un polímero de baja toxicidad que se degrada fácilmente en contacto con agua, basado en el ácido láctico.

Los polímeros biodegradables con mayor potencial en la industria en el futuro cercano son los polímeros a base de almidón, el ácido poliláctico PLA, el hidroxibutirato-co-hidroxivalerato $\mathrm{PHBV}$ y el ácido polihidroxibutírico $\mathrm{PHB}$.

Los polímeros a base de almidón se obtienen principalmente del trigo, el maíz, la papa o el arroz. Son termoplásticos y se pueden procesar por extrusión e inyección, pueden entrar en contacto con alimentos y actúan como barrera contra gases. Se descomponen entre 30 y 60 días y tienen una baja resistencia térmica.

El ácido poliláctico PLA se obtiene a partir de la fermentación de azúcar o maíz, es termoplástico y posee alta rigidez y fragilidad. Representa una buena barrera para gases y aromas, es transparente con buen acabado superficial. Se puede procesar por inyección, extrusión o termo formado.

El hidroxibutirato-co-hidroxivalerato PHBV pertenece a la familia de los polihidroxialcanoatos, más conocidos como PHA. Estos polímeros son poliésteres biodegradables que pueden ser producidos tanto químicamente empleando como reactivos butirolactona $y$ valerolactona y empleando compuestos de aluminio como catalizador; como biológicamente sintetizado a partir de azúcar o lípidos. Es más flexible y fácil de procesar que el PHB. El ácido polihidroxibutírico $\mathrm{PHB}$ es el polímero más empleado de los $\mathrm{PHA}$, es un termoplástico cristalino muy quebradizo y de rápida degradación, tiene una viscosidad muy baja lo que complica su extrusión.

Según sostienen Wolf, O.; Crank, M.; Patel, M.; Marscheider-Weidemann, F.; Schleich, J.; Hüsing, B. y Angerer, G. (2005) en función de sus propiedades y la tendencia en el precio, a futuro podemos esperar que algunos polímeros sean sustituidos por materiales biodegradables. Los polímeros a base de almidón tienen el potencial de sustituir parcialmente al polietileno de baja densidad LDPE, al polipropileno PP y al poliuretano PUR. El ácido poliláctico PLA podría sustituir parcialmente al polietileno tanto de alta como de baja densidad HDPE, LDPE, al polipropileno PP, al poliestireno PS, a las poliamidas PA, al tereftalato de polietileno PET. El PHBV es capaz de sustituir completamente al polipropi- 
leno PP y a los polietilenos de alta HDPE y baja densidad LDPE; y sustituir parcialmente al cloruro de polivinilo PVC, al tereftalato de polietileno PET y al poliuretano PUR. El PHB podría ser el reemplazo del polipropileno $\mathrm{PP}$ y sustituirá parcialmente al poliestireno PS, al polietileno de alta densidad HDPE y al acrilonitrilo butadieno estireno ABS.

Leonora Novaes de la empresa química Braskem aseguró al equipo editorial de la revista Tecnología del Plástico (2011), que el polietileno verde, cuya materia prima es eteno derivado de etanol de caña de azúcar, captura $\mathrm{CO}_{2}$ durante su ciclo de producción, ayudando a la reducción de emisiones de gases con efecto invernadero. La planta de producción de polietileno verde de Braskem funciona desde 2010, con una capacidad anual de 200.000 toneladas. Así mismo, Novaes anunció la construcción de una planta para producir polipropileno verde. Braskem asegura que por tener las mismas propiedades técnicas y de procesabilidad de las resinas fósiles, no es necesario invertir en equipos ni ajustes técnicos para procesar el plástico verde. Este es reciclable dentro de los procesos existentes y no contamina las fuentes de reciclaje de materiales de base petroquímica, como sí lo hacen otros biopolímeros. Entonces, no es necesario hacer una separación para reciclaje, entre el polietileno verde y el polietileno tradicional pues este no es un material nuevo sino una versión mejorada. Los polímeros de Braskem, aunque son de origen renovable no son biodegradables.

De la Cruz (2018) menciona otra investigación en bioplásticos desarrollada y patentada por la Universidad de Cornell, en Estados Unidos. Esta investigación estuvo bajo la responsabilidad del profesor Geoffrey Coates, tras la cual obtuvo plásticos biodegradables a partir de dióxido de carbono, un óxido de limonene (presente en la cáscara de naranja) y un catalizador, obteniendo un nuevo plástico denominado polylimonene.

Como catalizadores para la síntesis de biopolímeros se propone emplear enzimas. Según Barrera et al. (2015) la utilización de enzimas puede prevenir la generación de residuos mediante el uso de procesos catalíticos con alta selectividad, así como también prevenir o limitar el uso de reactivos orgánicos peligrosos.

Ya se puede encontrar en el mercado una amplia gama de aditivos derivados de almidones, que se aplican principalmente como plastificantes, modificadores de resistencia ante el impacto, agentes nucleantes y compatibilizantes para nano cargas. Estos aditivos están especialmente desarrollados para su uso con biopolímeros, principalmente ácido poliláctico PLA y polihidroxialcanoatos PHA.

En la feria nacional de plásticos realizada en Estados Unidos en 2012 hubo importantes lanzamientos de aditivos de base biológica que facilita el desarrollo de los biopolímeros hacia compuestos más competitivos. Según la reseña publicada por la revista Tecnología del Plástico en su edición de marzo (2012).

La empresa brasilera Nanox ha desarrollado una protección antimicrobiana natural, para ser integrada en el procesamiento de polímeros, creando una barrera antimicrobiana más eficiente para contener productos y haciéndolos más higiénicos. Cuenta con aceptación para uso en aplicaciones en contacto con alimentos ya que reduce el potencial de una contaminación microbiana y actúa en el control microbiológico, a través de las superficies activas de los polímeros tratados. Se comercializa con el nombre de Nanox Clean.

La empresa Teknor Apex presentó sus nuevos compuestos de biovinyl para PVC flexible, que incorporan plastificantes libres de ftalatos con propiedades físicas que serían comparables a las de los plastificantes tradicionales, pero que cuentan con una base $60 \%$ de 
fuentes renovables. Comecializados bajo el nombre de Dow Ecolibrium, son fabricados por Dow Chemical. Paul Kappus ha desarrollado el BioPVC que gracias a un aditivo que actúa como cebo para microorganismos, según dice, se biodegradará sin causar daños. La tecnología HyGuard de ColorMatrix, que ahora es una empresa de PolyOne. Ofrece un material completamente reciclable, de alto desempeño en la protección del producto empacado con tereftalato de polietileno PET gracias a su efecto de barrera para el oxígeno y una duración controlable de la vida en anaquel.

En cuanto a las cargas, la tecnología Excelite también producida por la empresa ColorMatrix de un agente espumante líquido para láminas de cloruro de polivinilo PVC, permite tener una estructura de celda uniforme y un excelente acabado superficial.

Las cargas empleadas con el fin de reducir peso, las espumas de tereftalato de polietileno PET son de alta resistencia a la temperatura y a productos químicos. La tecnología desarrollada por la empresa italiana B.C. Foam S.p.A, se usa en materiales compuestos de bajo peso, para aplicaciones en las industrias aeronáuticas y automotrices. Las instalaciones de producción y la propiedad intelectual para producir espumas de tereftalato de polietileno PET de alto desempeño, con muy altas densidades y producidas a través de un proceso especial de extrusión ha sido adquirida por la empresa alemana BASF.

Ya que los polímeros biodegradables tienen un rendimiento pobre, para producir plásticos útiles, es necesario que de forma paralela a su desarrollo se trabaje en los materiales de refuerzo.

López - Portillo (2018) en su libro La gran transición, escribe acerca de los retos y oportunidades de las tecnologías de crecimiento exponencial y menciona en primer lugar a la nanotecnología, término acuñado por Eric Drexler de la Universidad de Oxford para referirse a la fabricación precisa a nivel atómico. A esta escala la producción ocurre rápidamente, de manera directa y predecible.

Camacho, M.; Vega, J. y Campos, A. (2011) sostienen que el uso de polímeros biodegradables es limitado debido a problemas que se relacionan con tratamiento, rendimiento (barrera de gas y humedad son muy pobres) y costo. Mediante la aplicación de nanotecnología se abren nuevas posibilidades para mejorar no sólo las propiedades del material sino también la relación costo - eficiencia. Los nanocompuestos a base de biopolímeros son temas de investigación en el área de la ciencia de materiales, electrónica y ciencia biomédica. Un nanobiocompuesto es un material híbrido que consiste en una matriz biopolimérica reforzada con una fibra, una plaqueta o partícula que tiene una dimensión nanométrica. Debido a las partículas dispersas en la matriz biopolimérica, estos nanobiocompuestos exhiben una notable mejora en las propiedades mecánicas, térmicas, ópticas y fisicoquímicas en comparación con el polímero tradicional. Esas mejoras incluyen, por ejemplo, el aumento de módulos de elasticidad, fuerza y resistencia al calor, y la disminución de la permeabilidad a los gases y a la inflamabilidad.

Según Cruz, R.; Martínez, Y. y López, A. (2013) los biopolímeros, tanto los naturales como los sintéticos, tienen un potencial importante para ser usados como empaques para alimentos. Para ello es necesario contrarrestar sus limitadas propiedades mecánicas y de barrera integrando polímeros naturales con sintéticos derivados de hidrocarburos.

Gran parte de esta tecnología ahora cuenta con aprobación de la administración de drogas y alimentos de Estados Unidos FDA. La norma europea EN 13432 permite certificar los 
envases biodegradables con la finalidad de que la población pueda depositarlos junto con los desechos orgánicos, como restos de comida y poda de árboles.

\section{Reflexiones finales}

Toda la industria del plástico admite que este tiene que ser más sostenible. El futuro de los plásticos y el de la industria depende de hacerlos más seguros para la gente y para el planeta. Como sostiene Ortega (2011) se acerca el fin de la sostenibilidad como valor agregado, es posible que, en un futuro, las características de sostenibilidad dejen de ser un factor diferenciador para convertirse en un parámetro básico.

Estos esfuerzos por encontrar materiales plásticos que se descompongan rápidamente o en su defecto que sean reciclables, fomenta la concepción de productos de vida corta y desechables. Ya que toda tendencia genera una corriente opuesta, en contra tendencia a lo degradable y reciclable estará aprovechar esas características de durabilidad que tienen los plásticos para hacer productos de calidad, alto valor estético y simbólico, con una vida útil larga. Objetos de culto que se cuiden y resistan el paso de generaciones.

El naciente campo de los polímeros nano compuestos permitirá crear plásticos más sensibles y con capacidad de adaptarse a cambios en el entorno como temperatura, luz, presencia de vapores o líquidos. Estos plásticos cada vez más inteligentes tendrán presencia importante en los campos de la microelectrónica, los textiles, la construcción, el transporte, la industria de envases para alimentos, los materiales compuestos que podrán ser más resistentes y livianos y la salud incluyendo el reemplazo de tejidos y órganos humanos.

Si estas propuestas resultan exitosas tal vez nuestro futuro no esté en el camión de la basura y podamos promover una mayor utilización de plásticos no contaminantes que conserven la libertad para diseñar que caracteriza a estos materiales redefiniendo lo que un crítico alemán denominó Plastikoptimismus.

\section{Bibliografía}

Annicchiarico, S. (2012). La cultura del plástico. en Kartell the culture of plastics. Milán, Italia: Taschen.

Barrera, K.; Peponi, L.; Navarro, I.; Alpizar, A.; Marcos, A.; Kenny, J.; ... Martínez, A. (2015). Polimerización enzimática para la síntesis de biopolímeros. Revista de plásticos modernos, 110 (703) 22-28.

Buranyi, S. (13 de noviembre de 2018). The plastic backlash: what's behind our sudden rage - and will it make a difference? The Guardian. Recuperado de: https://www.theguardian. com/environment/2018/nov/13/the-plastic-backlash-whats-behind-our-sudden-rageand-will-it-make-a-difference

Camacho, M.; Vega, J. y Campos, A. (2011). Uso de nanomateriales en polímeros para la obtención de bioempaques en aplicaciones alimentarias. Revista de la Sociedad Química del Perú, 77(4), 292-306. Recuperado en 11 de diciembre de 2018, de http://www.scielo. org.pe/scielo.php?script=sci_arttext\&pid=S1810-634X2011000400007\&lng=es\&tlng=es 
Cruz, R.; Martínez, Y. y López, A. (2013). Biopolímeros y su integración con polímeros convencionales como alternativa de empaque de alimentos. Temas selectos de ingeniería de alimentos, (7-2), 42-52.

De la Cruz, S. (2018). Qué son los plásticos verdes o bioplasticos. Diario Ecología. Recuperado de: http://diarioecologia.com/que-son-los-plasticos-verdes-o-bioplasticos/

Eun, J.; Jae, S.; Jun, W.; Jun, H.; Kim, B.; Lee, H.; ...Lee, S. (2018). One-step fermentative production of aromatic polyesters from glucose by metabolically engineered Escherichia coli strains. Nature Communications 9 (1). doi: 10.1038/s41467-017-02498-w

Equipo editorial de Tecnología del Plástico. (2011). Polímeros verdes de Braskem, buena química con el mercado. Tecnología del Plástico, (27), 23.

Equipo editorial de Tecnología del Plástico. (2012). Resinas y aditivos en NPE 2012. Tecnología del Plástico, (32), 26-27.

Freinkel, S. (2012). Plástico: un idilio tóxico. Barcelona, España: Tusquets.

Lopez - Portillo, J. (2018). La gran transición: retos y oportunidades del cambio tecnológico exponencial. México: Fondo de cultura económica.

Manahan, S. (2007). Introducción a la química ambiental. México: Reverté.

Ortega, M. (2011). ¿Se acerca el fin de la sostenibilidad como factor agregado? Tecnología del Plástico, (26), 4.

Parker, L. (2018). Plástico. National Geographic en español. 42 (6), 28-55.

Smith, R. y Lourie, B. (2009). Slow death by rubber duck: the secret danger of everyday things. Berkley, CA, USA: Counterpoint.

Wolf, O.; Crank, M.; Patel, M., Marscheider-Weidemann, F.; Schleich, J.; Hüsing, B. y Angerer, G. (2005). Tehno-Economic Feasibility of Large-Scale Production of Bio-Based Polymers in Europe. Fraunhofer ISI. Recuperado de: https://www.researchgate.net/pu blication/44262558_Tehno-Economic_Feasibility_of_Large-Scale_Production_of_BioBased_Polymers_in_Europe

\begin{abstract}
In recent times, politicians, environmental activists, journalists and other opinion leaders have directed their weapons against plastics. This bad concept was born as a result of the changes in the environment as a result of the use of new sources of energy, both nuclear and fossil fuels and the development of the petrochemical industry, especially the plastics that occurs from the discovery of the oil. However, despite environmental considerations, plastic has built our world to the point where today it is difficult to imagine our life without it.

Many designers have argued since the mid-twentieth century, that good quality items can be beautiful and do not have to cost a lot of money. The couple of designers formed by Charles and Ray Eames proposed to provide people the best at the lowest possible price. They used in their designs aluminum, plywood, some other materials and mainly plastic. French designer Philipe Starck, agrees with his predecessors. He likes this material because of its democratic possibilities and because unlike natural materials it is a product of human intelligence, perfect for our human civilization. He argues that from an ecological perspec-
\end{abstract}


tive it is better to use plastic instead of wood. The Danish designer Verner Panton was not inspired by natural fibers or wood. He imagined organic forms and garish colors. He was attracted by the new materials that emerged after the Second World War, steel profiles, plywood and especially plastics. At the beginning of the sixties he already had a reputation for his playful designs. He furnished a hotel with inflatable plastic furniture, designed retro-lit plastic wall panels, UFO-shaped lamps and chairs with rolled metal cylinders and, thanks to plastic injection molding technology, created his famous one-piece chair.

With a more critical look, many plastic objects have been questioned by people in the same industry. One inexpensive evolution of the one-piece chair was the monoblock chair in which the minimum possible material is used. Rolf Fehlbaum, president of Vitra Design says that you can perceive the idea of low price implicit in the product, that the chair suggests a moral minimum: how to make them as cheap as possible so that they last a few years and then you can throw them away.

Then it is possible to ask if it is possible to protect the environment without dispensing with the advantages presented by plastics and their properties and that these are once again considered a solution to environmental problems as they were in 1936 when a woman said after visiting the exhibition The Wonderful World of Chemistry, "It's wonderful how DuPont is improving nature."

Since the entire plastics industry admits that this has to be more sustainable, the future of plastics and that of the industry depends on making them safer for people and for the planet.

There are a lot of attempts to obtain the so-called "green plastics". This is the sector of the industry that grows the fastest, approximately $10 \%$ per year. There are those who are experimenting with renewable raw materials, returning the industry to its roots by using plant material as in the celluloid era.

If these proposals are successful maybe our future is not in the garbage truck and we can promote a greater use of non-polluting plastics that preserve the freedom to design that characterizes these materials redefining what a German critic called Plastikoptimismus.

Keywords: Plastics - Industrial ecology - Sustainability - Green plastics - Renewable raw materials - Bioplastics.

Resumo: Nos últimos tempos políticos, ativistas ambientais, jornalistas e outros líderes de opinião direcionaram suas armas contra os plásticos. Este equívoco é o resultado de mudanças no ambiente resultantes da utilização de novas fontes de energia, tanto nuclear como os combustíveis fósseis e para o desenvolvimento da indústria petroquímica em plásticos particulares dados a partir da descoberta de óleo. No entanto, apesar das considerações ambientais, o plástico construiu nosso mundo até o ponto em que hoje é difícil imaginar nossa vida sem ele.

Muitos designers têm mantido desde meados do século XX, que itens de boa qualidade podem ser bonitos e não precisam custar muito dinheiro. $\mathrm{O}$ casamento de estilistas formados por Charles e Ray Eames propunha proporcionar às pessoas o melhor ao menor preço possível, por isso usavam em seus projetos alumínio compensado, alguns outros materiais e principalmente plástico. A opinião do designer francês Philipe Starck, concor- 
da com a de seus antecessores. Ele gosta desse material por causa de suas possibilidades democráticas e porque, ao contrário dos materiais naturais, é um produto da inteligência humana, perfeito para nossa civilização humana. Ele argumenta que, desde uma perspectiva ecológica, é preferível usar plástico em vez de madeira. $\mathrm{O}$ designer dinamarquês Verner Panton não foi inspirado por fibras naturais ou madeira. Ele imaginava formas orgânicas e cores berrantes. Ele foi atraído pelos novos materiais que surgiram após a Segunda Guerra Mundial, perfis de aço, compensados e especialmente plásticos. No início dos anos sessenta, ele já tinha uma reputação por seus projetos lúdicos. Ele mobiliou um hotel com painéis de plástico infláveis, projetou painéis de parede de plástico retroiluminados, lâmpadas e cadeiras em forma de UFO com cilindros de metal laminados e, graças à tecnologia de moldagem por injeção de plástico, criou sua famosa cadeira de uma peça. Com uma aparência mais crítica, muitos objetos de plástico foram questionados por pessoas do mesmo setor. Uma evolução mais econômica da cadeira de uma peça foi a cadeira monobloco na qual é usado o material mínimo possível. Rolf Fehlbaum, presidente de estados Vitra Design diz que se pode perceber a ideia de baixo preço implícito no produto, a cadeira sugere um mínimo moral: torná-los o mais barato possível para durar alguns anos e, em seguida, pode jogar.

Em seguida, a questão de saber se é possível proteger o meio ambiente sem sacrificar as vantagens oferecidas pelos plásticos e suas propriedades e estes novamente ser considerados uma solução para os problemas ambientais como foi em 1936, quando uma mulher disse depois de visitar a exposição Wonderful of Chemistry, "É maravilhoso como a DuPont está melhorando a natureza”.

Como toda a indústria de plásticos admite que isso tem que ser mais sustentável, o futuro dos plásticos e da indústria depende de torná-los mais seguros para as pessoas e para o planeta.

Há muitas tentativas para obter os chamados "plásticos verdes". Este é o setor da indústria que cresce mais rápido, aproximadamente $10 \%$ ao ano. Há aqueles que estão experimentando matérias-primas renováveis, retornando a indústria às suas raízes usando material vegetal como na era do celulóide.

Se estas propostas forem bem sucedidos, talvez o nosso futuro não está no caminhão de lixo e pode promover uma maior utilização de plástico limpo para manter a liberdade de design que caracteriza estes materiais redefinindo o que um crítico alemão chamado Plastikoptimismus.

Palavras chave: plásticos - ecologia industrial - sustentabilidade - plásticos verdes - matérias primas renováveis - bioplásticos. 